\title{
Predicting wood stiffness of lodgepole pine trees using acoustic tools and green density
}

\author{
by James D. Stewart ${ }^{1}$, Ross Koppenaal ${ }^{2 \dagger}$, Antoine Lalumière ${ }^{2}$ and Roger J. Whitehead2"*
}

\begin{abstract}
Upstream identification of wood properties using non-destructive testing methods such as acoustic velocity (AV) measurements is important for optimizing allocation of wood to mills or products. We evaluated the effectiveness of field AV measurement tools in predicting lodgepole pine wood stiffness (modulus of elasticity, MOE) as measured by Silviscan on wood samples. AV was measured on trees and logs from six sites in Alberta and British Columbia. We evaluated the effect on MOE estimation of calculating averages of the adjustment factor $k$ and of green density (GD) at different spatial scales from individual tree to population. The effect of using forest inventory variables on MOE prediction were also examined. Prediction of tree-level MOE from tree-level measurements of AV, $k$ and GD resulted in $\mathrm{R}^{2}$ values of 0.59 . Using estimates of $k$ and GD averaged at plot, site or population scales significantly diminished the $\mathrm{R}^{2}$ of the MOE predictions at tree level. Predicting MOE at plot or stand level from corresponding averages of AV, $k$ and GD gave $\mathrm{R}^{2}$ values $>0.8$. Including inventory variables in tree-level MOE predictions increased the $\mathrm{R}^{2}$ to 0.62 . AV measurements can give operationally useful estimates of MOE in lodgepole pine trees at the stand level.
\end{abstract}

Keywords: modulus of elasticity, wood stiffness, acoustic velocity, non-destructive testing, Pinus contorta

\section{RÉSUMÉ}

L'identification hâtive des propriétés du bois au moyen de méthodes d'investigation non destructives comme la mesure de la vitesse de propagation du son (acoustic velocity - $A V$ ) est importante pour assurer une allocation optimale des bois aux usines ou pour la fabrication de certains produits. Nous avons testé l'efficacité des instruments de terrain pour mesurer l'AV pour prédire la force du bois de pin lodgepole (module d'élasticité, MOE) qui serait obtenue par Silviscan sur des échantillons de bois. Les mesures d'AV ont été prises sur des arbres et des billots provenant de six sites en Alberta et en Colombie-Britannique. Nous en avons ensuite voulu savoir comment le fait de calculer les moyennes pour le facteur ce correction $k$ et la densité à l'état vert (GD) à différentes échelles spatiales, de l'arbre jusqu'à la population, pouvait influencer l'estimation du MOE. L'effet d'utiliser les données d'inventaire forestier sur la prévision du MOE a également été étudié. La prévision du MOE à l'échelle de l'arbre à partir de ses mesures d'AV, de $k$ et de GD a donné des valeurs de $\mathrm{R}^{2}$ de 0,59 . L'utilisation de moyennes pour $k$ et GD estimées à l'échelle de la placette, du site ou de la population a réduit considérablement les valeurs de $\mathrm{R}^{2}$ pour les MOE estimées à l'échelle de l'arbre. La prévision du MOE à l'échelle de la placette ou du peuplement à partir des moyennes correspondantes de $\mathrm{AV}, k$ et GD a donné des valeurs de $\mathrm{R}^{2}>0,8$. Le fait d'ajouter les variables d'inventaire pour prédire le MOE à l'échelle de l'arbre a fait passer le $\mathrm{R}^{2}$ à 0,62 . Les mesures d'AV permettent une estimation opérationnelle intéressante du MOE pour le pin lodgepole à l'échelle du peuplement.

Mots-clés: module d'élasticité, force du bois, vitesse de propagation du son, tests non destructifs, Pinus contorta,

\section{Introduction}

Lodgepole pine (Pinus contorta Dougl. ex Loud. var. latifolia Engelm.) is widespread in western North America, growing in a broad range of climate and ecological site types, from the montane into the subalpine (Lotan and Critchfield 1990). Lodgepole mostly occurs in relatively uniform single-species even-aged stands, making it a high quality fibre resource valuable for both solid wood and pulp-based products (Koch 1996). The suitability of lodgepole pine for visual grade stud and dimension lumber, and especially for machine stressrated lumber, depends on meeting specific standards for strength and stiffness of the wood (Josza and Middleton 1994). Optimal allocation of lodgepole pine to the most appropriate mill and process can be improved by segregating trees or logs by wood stiffness before processing (Murphy and Cown 2015).

Acoustic velocity is an accurate and reliable indicator of wood stiffness (modulus of elasticity, MOE) (Huang et al. 2003), and is the basis for the non-destructive evaluation of stiffness in logs and standing trees using acoustic tools (Wang 2013). Acoustic tools provide a more accurate indication of wood properties than visual log grading determined solely from external characteristics such as diameter and form (Edlund et al. 2006), and measurements can be rapidly performed in the forest, on landings, or in sort yards. Given the often large natural variation in MOE within and between

\footnotetext{
${ }^{1}$ Natural Resources Canada, Canadian Forest Service, Canadian Wood Fibre Centre, Edmonton, AB; correspondence: jim.stewart2@canada.ca

${ }^{2}$ Natural Resources Canada, Canadian Forest Service, Canadian Wood Fibre Centre, Victoria, BC; † deceased * retired
} 
trees and stands (Grabianowski et al. 2006), determining the distribution of MOE in the forest inventory is critical for efficient resource allocation and recovery of valuable highstiffness structural lumber and veneer. Acoustic tools for standing trees provide in situ measurements of acoustic velocity in the outerwood, and can be implemented in preharvest stand evaluation as part of the forest inventory and management planning processes. Evaluation of wood quality characteristics of a stand early in the supply chain (pre-harvest) enables strategic allocation of the harvested trees to their optimal end use by directing material to the appropriate processing line or mill. However, non-destructive evaluation of wood quality very early in the supply chain often comes with a tradeoff in measurement reliability, and weaker correlations with the mechanical properties of the final wood product. This is the case with standing tree acoustic tools, which allow evaluation of wood stiffness prior to harvest and monitoring at earlier stages of stand development, but at the expense of a higher degree of uncertainty than with resonance-based acoustic tools used on logs (Mora et al. 2009). The reasons for this relate to fundamental differences in what property is being measured and in how the stress wave propagates in logs and trees. These differences are reviewed in Legg and Bradley (2016) and discussed further below.

Standing tree acoustic measurements are based on the time-of-flight (TOF) velocity of a single stress wave between two piezoelectric sensors penetrating approximately one centimeter into the sapwood and placed about one metre apart, centered at approximately breast height. The propagation of the stress wave from a TOF tool is assumed to be limited (by sensor location and depth) to a section of outerwood defined by the longitudinal distance between the sensors and an undefined but limited radial span within which the acoustic wave travels. Therefore, TOF velocity measurements in mature trees are presumed to be largely dominated by higher stiffness mature wood and less representative of the whole stem in cross-section and length than resonancebased log measurements. Due to the localized nature of stress-wave propagation using tree TOF tools, they are considered less reliable for predicting wood quality than log acoustic tools using the resonance method (Raymond et al. 2008; Fischer et al. 2015, ). Multiple TOF measurements taken around the stem will better characterize the variation in wood stiffness in the outerwood (Lachenbruch et al. 2010); however, accounting for radial variation in stiffness is difficult to do in standing trees (Legg and Bradley 2016). Despite their inherent limitations, TOF tools have shown potential for rapid pre-harvest screening of wood stiffness (Paradis et al. 2013), including in-forest assessment of site (Auty and Achim 2008), fertilization (Filipescu et al. 2016), and density treatment effects (Krajnc et al. 2019) on wood quality, and selection for improved wood mechanical property traits in progeny trials (Filipescu et al. 2018).

Consensus on the performance and reliability of tree TOF tools is lacking however, as different studies have reported weak (Fischer et al. 2015), moderate (Paradis et al. 2013), and strong (Grabianowski et al. 2006) predictive relationships with lumber and veneer MOE. Several influential factors complicate comparisons among these studies including tree age and diameter (Chauhan and Walker 2006,), measurement of corewood (juvenile wood) vs. outerwood (mature wood) (Mora et al. 2009), measurement intensity around the stem (Wagner et al. 2003), and the use of different TOF tools (Wang 2013). Given the inherent variability of TOF measurements at the tree level, it has been suggested that TOF acoustic tools can best be utilized to provide stand-level estimates of average wood stiffness to help inform stand selection decisions in accordance with mill demands for specific lumber grades (Moore et al. 2013).

Due to the greater uncertainty of standing tree TOF measurements in predicting wood stiffness, an acceptable level of conformance with log resonance measurements or other accepted standards (e.g., static bending tests, SilviScan analysis) is necessary to validate the application of TOF tools (Wang 2013). Notwithstanding the strength of the relationship between TOF and resonance measurements, TOF velocities are consistently higher than those from corresponding resonance measurements due to differences in stress-wave propagation and the measurement technology used. This intrinsic bias in TOF measurements requires adjustment to resonance equivalent values before calculating MOE values. The tree TOF/log resonance velocity ratio $(k)$ can be used for adjustment of tree TOF measurements and, combined with wood green density (GD), can be used to estimate dynamic MOE in standing trees (Andrews 2003).

While values for $k$ have been established for several conifer species, ranging between 1.07 and 1.36 (Wang 2013), $k$ has not been determined for lodgepole pine. Although a single species-wide $k$ adjustment factor would be convenient to apply operationally, if $k$ is sensitive to variation in tree growth, site and stand characteristics then wood quality estimates from those $k$-adjusted standing tree TOF measurements will be less reliable. In this regard, the $k$-adjustment method has not been adequately tested for sensitivity to the variation in standard forest inventory metrics such as height, diameter, and stand stocking. Over a wide range of one or more of these inventory variables it is possible that tree and log tool velocity measurements could be affected differentially, affecting $k$, as was reported for diameter at breast height $(\mathrm{DBH})$ in radiata pine (Pinus radiata $\mathrm{D}$. Don) (Chauhan and Walker 2006) and ponderosa pine (Pinus ponderosa Douglas ex C. Lawson) (Wang et al. 2007). While these studies examined the effects of DBH and stand age on $k$, other forest inventory growth and stocking metrics were not considered. For example, the proportion of juvenile wood to mature wood may vary significantly over a wide range in values for height, diameter, live crown ratio or stand density, and could affect $k$ alone or in interaction, since TOF and resonance-based tools measure velocity through the outerwood and the whole stem cross-section, respectively.

To reduce the time and expense of acquiring GD measurements needed to estimate dynamic MOE in an operational context, it has been suggested that accurate estimates of velocity-based MOE can be obtained using a stand average or constant GD value (Wielinga et al. 2009). However, the accuracy of such MOE estimates using a stand average GD depends on within-stand variability in GD being low relative to the variation in acoustic velocity (Wielinga et al. 2009). Watt and Trincado (2014) demonstrated that use of a species constant value for GD, compared with using tree-level values, results in substantial error in prediction of MOE from acoustic measurements in radiata pine. The variation of GD in 
lodgepole pine needs to be evaluated to determine the most appropriate scale over which to average it for use in calculating MOE.

In this study, standing tree TOF and log resonance acoustic tools were evaluated for their utility and reliability in predicting wood stiffness (dynamic MOE) in mature lodgepole pine trees and corresponding logs from six sites in Alberta and interior British Columbia (B.C.). The specific objectives were to:

1. establish the relationship between TOF measurements from standing trees and resonance velocity measurements in logs from those trees, and determine the value of and variation in $k$ (TOF/resonance ratio) for adjusting tree TOF measurements to their equivalent resonance values;

2. evaluate estimates of MOE derived from AV measurements on trees against SilviScan measures of MOE, using values of $\mathrm{V}_{\mathrm{TOF}}, k$ and GD averaged at scales from tree to population; and,

3. evaluate the potential of using forest inventory-based indices to improve estimates of $\mathrm{MOE}$.

\section{Methods}

Study sites and silvicultural prescription

The data for this study came from six long-term silvicultural research sites with mature lodgepole pine stands located in the central foothills of Alberta and southeastern B.C., Canada (Table 1).
The two B.C. sites, Cranbrook and Parson, were older stands (96 years old) and were commercially thinned in late rotation (at $80-81$ years). The four Alberta sites were younger stands (65-77 years old), three of which, MacKay, Teepee Pole Flat and Teepee Pole North, were pre-commercially thinned early in the rotation (at 22-26 years). The remaining site in Alberta, McCardell, was thinned at approximately mid-rotation (40 years). Thinning treatments (1.6- $\mathrm{m}$ to 5.0 $\mathrm{m}$ spacing) were applied at all sites, resulting in the latest stand density measurements ranging from 252 to 2953 stems per hectare (Table 1). Fertilizer (ammonium nitrate) treatments were applied at only two of the sites (Cranbrook and McCardell), separately and in combination with thinning treatments. Each site retained an untreated control plot. Further information on the sites and silvicultural treatments can be found in Whitehead and Russo (2005) and Stewart et al. (2006).

\section{Acoustic velocity measurements}

At each site, standing tree TOF-based acoustic velocity $\left(\mathrm{V}_{\mathrm{TOF}}\right)$ was measured on five randomly selected co-dominant trees (within one standard deviation of the mean DBH of codominant trees) from permanent sample plots located in each silvicultural treatment (untreated, thinned, and/or fertilized). Ten to 30 trees were sampled per site, except at the Teepee Pole North site where only four standing trees were measured due to tool malfunction. As a result, there were acoustic measurements for 94 standing trees.

Table 1. Site description, silvicultural treatments and stand characteristics

\begin{tabular}{|c|c|c|c|c|c|}
\hline Location & $\begin{array}{l}\text { Stand Age } \\
\text { (years) }\end{array}$ & $\begin{array}{l}\text { Age at treatment } \\
\text { (treatment year) }\end{array}$ & Silvicultural treatment & $\begin{array}{c}\text { Stand } \\
\text { density } \\
\text { (sph) }\end{array}$ & $\begin{array}{l}\text { Mean } \\
\text { DBH } \\
(\mathrm{cm})\end{array}$ \\
\hline $\begin{array}{l}\text { Cranbrook, BC } \\
49^{\circ} 25.0^{\prime} \mathrm{N}, 115^{\circ} 37.1^{\prime} \mathrm{W}\end{array}$ & 96 & $80(1993)$ & $\begin{array}{l}\text { Not thinned or fertilized } \\
\text { Heavily Thinned ( } 4 \mathrm{~m} \text { spacing) } \\
\text { Fertilized ( } 480 \mathrm{~kg} / \mathrm{ha} \mathrm{N}) \\
\text { Thinned \& Fertilized }\end{array}$ & $\begin{array}{c}1650 \\
464 \\
1008 \\
559\end{array}$ & $\begin{array}{l}17.5 \\
24.7 \\
20.0 \\
23.0\end{array}$ \\
\hline $\begin{array}{l}\text { Parson, BC } \\
50^{\circ} 59.3^{\prime} \mathrm{N}, 116^{\circ} 41.2^{\prime} \mathrm{W}\end{array}$ & 96 & $81(1994)$ & $\begin{array}{l}\text { Not thinned } \\
\text { Heavily Thinned ( } 5 \mathrm{~m} \text { spacing) }\end{array}$ & $\begin{array}{l}925 \\
252\end{array}$ & $\begin{array}{l}20.9 \\
26.3\end{array}$ \\
\hline $\begin{array}{l}\text { MacKay, AB } \\
53^{\circ} 32.7^{\prime} \mathrm{N}, 115^{\circ} 32.3^{\prime} \mathrm{W}\end{array}$ & 77 & $22(1954)$ & $\begin{array}{l}\text { Not thinned } \\
\text { Lightly Thinned ( } 1.96 \mathrm{~m} \text { spacing) } \\
\text { Heavily Thinned ( } 3.65 \mathrm{~m} \text { spacing) }\end{array}$ & $\begin{array}{c}2953 \\
1705 \\
640\end{array}$ & $\begin{array}{l}12.9 \\
16.5 \\
23.0\end{array}$ \\
\hline $\begin{array}{l}\text { Teepee Pole Flat, AB } \\
51^{\circ} 54.1^{\prime} \mathrm{N}, 115^{\circ} 11.2^{\prime} \mathrm{W}\end{array}$ & 68 & $25(1967)$ & $\begin{array}{l}\text { Not thinned } \\
\text { Lightly Thinned (1.6 m spacing) } \\
\text { Heavily Thinned ( } 3.2 \mathrm{~m} \text { spacing) }\end{array}$ & $\begin{array}{c}2205 \\
1621 \\
751\end{array}$ & $\begin{array}{l}16.4 \\
16.0 \\
21.2\end{array}$ \\
\hline $\begin{array}{l}\text { Teepee Pole North, AB } \\
51^{\circ} 53.8^{\prime} \mathrm{N}, 115^{\circ} 09.7^{\prime} \mathrm{W}\end{array}$ & 68 & $25(1967)$ & $\begin{array}{l}\text { Not thinned } \\
\text { Lightly Thinned ( } 1.6 \mathrm{~m} \text { spacing) } \\
\text { Heavily Thinned ( } 3.2 \mathrm{~m} \text { spacing) }\end{array}$ & $\begin{array}{c}2126 \\
1383 \\
721\end{array}$ & $\begin{array}{l}15.5 \\
16.9 \\
21.5\end{array}$ \\
\hline $\begin{array}{l}\text { McCardell, } \mathrm{AB} \\
53^{\circ} 11.8^{\prime} \mathrm{N}, 117^{\circ} 11.1^{\prime} \mathrm{W}\end{array}$ & 65 & $40(1984)$ & $\begin{array}{l}\text { Not thinned or fertilized } \\
\text { Thinned }(2.2 \mathrm{~m} \text { spacing) } \\
\text { Lightly Fertilized }(180 \mathrm{~kg} / \mathrm{ha} \mathrm{N}) \\
\text { Heavily Fertilized ( } 360 \mathrm{~kg} / \mathrm{ha} \text { N) } \\
\text { Thinned \& Lightly Fertilized } \\
\text { Thinned \& Heavily Fertilized }\end{array}$ & $\begin{array}{l}2072 \\
1805 \\
2340 \\
2406 \\
1537 \\
1671\end{array}$ & $\begin{array}{l}16.2 \\
16.2 \\
14.6 \\
17.1 \\
18.1 \\
16.7\end{array}$ \\
\hline
\end{tabular}

Note: measurement year: Cranbrook and Parson (2009), MacKay (2013), McCardell (2014), Teepee Pole (2015) 
The $\mathrm{V}_{\mathrm{TOF}}$ measurements were taken on standing trees with a Hitman ST300 (Fibre-gen Ltd., Christchurch, New Zealand) TOF-based tool using probes with piezoelectric sensors inserted approximately 0.5 and $1.7 \mathrm{~m}$ above ground. The ST300 tool measures the mean acoustic velocity of the four middle values from a set of eight hammer hits to the transmitter probe. Measurements were taken at three circumferential positions, $120^{\circ}$ apart on the stem, to determine the average $\mathrm{V}_{\text {TOF }}$ value for a tree; avoiding obvious stem anomalies and defects, including large knots and compression wood. Standing tree $\mathrm{V}_{\mathrm{TOF}}$ was determined based on the equation:

$$
\text { [1] } V_{T O F}=S / t \text {, }
$$

Where $S$ is the distance between the transmitter and receiver probes $(\mathrm{m})$, and $t$ is stress wave transmission time (i.e., TOF) (Wang et al. 2007).

The trees were felled to produce a merchantable stem from stump height $(30 \mathrm{~cm})$ to merchantable top $(10 \mathrm{~cm}$ and $7.5 \mathrm{~cm}$ diameter for the B.C. and Alberta sites, respectively, based on provincial standards). The stem was then cut into three equal length logs (lower, middle and upper) cut between breast height $(1.3 \mathrm{~m})$ and the merchantable top, corresponding to the lower, middle and upper bole. Log-level acoustic velocity $\left(\mathrm{V}_{\mathrm{RES}}\right)$ was measured on the whole merchantable stem and each component log with a Hitman HM200 resonance-based tool (Fibre-gen Ltd., Christchurch, New Zealand), comprising 105 whole stems and 313 logs (lower, middle and upper stem). The HM200 tool measures the area-weighted cross-sectional average velocity over the length of the log based on the equation:

$$
\text { [2] } \quad V_{R E S}=2 L f_{0}
$$

Where $f_{0}$ is the fundamental resonance frequency of an acoustic wave signal $(\mathrm{Hz})$ and $L$ is log length $(\mathrm{m})$ (Carter et al. 2006). The average of three repeated measurements of loglevel $V_{R E S}$ were recorded for each log segment.

Green wood density was determined by water displacement (ASTM International 2017) on discs cut from the lower end of each log section and at the merchantable top to obtain an average log GD based on two discs for each section (lower, middle and upper logs) and on four discs for the whole merchantable stem.

We estimated dynamic modulus of elasticity of logs $\left(\mathrm{MOE}_{\mathrm{RES}}\right)$ from acoustic velocity and GD using the equation:

$$
\text { [3] } M O E_{R E S}=V^{2} x \mathrm{GD}
$$

Where $V(\mathrm{~km} / \mathrm{s})$ is acoustic velocity as measured by the HM200 ( $\left.\mathrm{V}_{\mathrm{RES}}\right)$, and GD $\left(\mathrm{kg} / \mathrm{m}^{3}\right)$ is green wood density (Andrews 2003). This equation is valid for resonance acoustic velocity; however, since $\mathrm{V}_{\text {TOF }}$ measurements are consistently higher than $V_{\text {RES }}$ measurements, common practise was followed and the $\mathrm{V}_{\mathrm{TOF}}$ values were adjusted to match the $\mathrm{V}_{\mathrm{RES}}$ values before calculating dynamic modulus of elasticity of trees $\left(\mathrm{MOE}_{\mathrm{TOF}}\right)$. The adjustment factor $(k)$ is the ratio $\mathrm{V}_{\mathrm{TOF}} / \mathrm{V}_{\mathrm{RES}}$ calculated for each tree. We also calculated $k$ as averages at different scales, namely, for each of the 20 plots, for each of the six sites, and for the whole population. The adjusted $\mathrm{V}_{\mathrm{TOF}}$ (Eq. 4) was used in place of $\mathrm{V}_{\mathrm{RES}}$ in Equation 3 to calculate $\mathrm{MOE}_{\mathrm{TOF}}$.

\section{[4] adjusted $V_{T O F}=V_{T O F} / k$}

\section{Forest inventory variables}

Diameter, height, and height to the base of the live crown were measured for each sampled tree. Crown length, live crown ratio and basal area of larger trees was calculated for each sampled tree. In addition, we retrieved data on stand density and basal area at sampling, age at thinning treatment, and years since treatment from long-term mensuration data from these sites (Whitehead and Russo 2005; Stewart et al. 2006). To account for differences in treatment age and stand development, we calculated an index of the effect of the thinning treatments as the Stand Density Index (Reineke 1933) at an index age of 50 years for each treatment plot (Table 2).

\section{SilviScan analysis}

Disc samples for SilviScan analysis were cut at five stem locations: stump height, breast height (base of lower log), base of middle log (top of lower log), base of top log (top of middle $\log$ ), and merchantable top (top of top log). Pith-to-bark blocks were cut from the discs and analyzed by the EvaluTree lab at FPInnovations (Vancouver, BC) using the SilviScan-3 system. In preparation for SilviScan analysis, the wood blocks were extracted with acetone to remove resins, and air-dried to $8 \%$ moisture content, after which a small clear radial strip (2 mm tangential x $7 \mathrm{~mm}$ longitudinal) was cut from each block. SilviScan-predicted modulus of elasticity $\left(\mathrm{MOE}_{\mathrm{SS}}\right)$ is based on a model that combines density measured using $\mathrm{X}$ ray densitometry and the variation in the intensity of the $\mathrm{X}$ ray diffraction profile (Evans 2006). For each radial strip, the sample MOE was calculated as the ring area-weighted average across the entire pith-to-bark distance. SilviScan MOE was calculated for each log as the mean of the two end-disc values. Tree age was estimated by counting the number of rings in the stump samples.

Table 2. Forest inventory variables used in the analyses

\begin{tabular}{lll}
\hline Name & Category & Description \\
\hline Sph_final & stocking & Stem density at sampling $(\mathrm{stems} / \mathrm{ha})$ \\
BA.ha & stocking & Stand basal area at sampling $\left(\mathrm{m}^{2} / \mathrm{ha}\right)$ \\
SDI50 & stocking & Stand Density Index at stand age 50 years \\
Trt_age & age & Stand age at the time of thinning treatment (years) \\
Yrs_since_trt & age & Number of years between treatment and sampling \\
Tree_age & age & Tree age at sampling (years) \\
Dbh & stem size & Diameter at breast height $(1.3 \mathrm{~m})$ at sampling $(\mathrm{cm})$ \\
Height & stem size & Total tree height at sampling $(\mathrm{m})$ \\
Ht2LC & crown & Height to the base of the live crown $(\mathrm{m})$ \\
CrLen & crown & Length of the live crown $(\mathrm{m})$ \\
LCR & crown & Live Crown Ratio (length of live crown / total height $)$ \\
BAL & competition & Sum of the stem basal area of all trees larger than \\
& & the subject $\left(\mathrm{m}^{2} / \mathrm{ha}\right)$ \\
\hline
\end{tabular}




\section{Data analysis}

All the following analyses were performed using the R statistical platform (R Core Team 2013).

For each of $\mathrm{MOE}_{\mathrm{S} S}, k$, and $\mathrm{GD}$, the variance components of the different hierarchical levels of the study (site, plot, and residual tree) were estimated by fitting the following intercept-only linear random-effects model for each independent variable (R package nlme, Pinheiro et al. 2020):

$$
\text { [5] } y_{\mathrm{ijk}}=\mu+b_{\mathrm{i}}+\mathrm{b}_{\mathrm{ij}}+\varepsilon_{\mathrm{ijk}}
$$

Where $y_{\mathrm{ijk}}$ denotes the response of the dependent variable measured on the $\mathrm{k}^{\text {th }}$ tree from the $\mathrm{j}^{\text {th }}$ plot at the $\mathrm{i}^{\text {th }}$ site, $\mu$ denotes the model intercept or grand mean, $b_{i}$ denotes the random effect for site $(i=1, \ldots, 6), b_{i j}$ denotes the random effect for plot nested in site $(j=1, \ldots, 20)$, and $\varepsilon_{i j k}$ represents the within-group errors. The random effects and within-group errors were assumed to be independent with a multivariate normal distribution, with $\mathrm{b}_{\mathrm{i}} \sim \mathrm{N}\left(0, \Psi_{1}\right), \mathrm{b}_{\mathrm{ij}} \sim \mathrm{N}\left(0, \Psi_{2}\right)$ and $\varepsilon_{\mathrm{ijkl}}$ $\sim \mathrm{N}\left(0, \sigma_{e}^{2}\right)$. The $\Psi_{1}$ and $\Psi_{2}$ are the variance-covariance matrices for the different levels of random effects-site and plot, respectively. The relative contribution of variance at each level was calculated as a percentage of the total variance.

Given the above variance structure for these variables, we tested how using $k$ and GD averaged at different hierarchical scales to calculate $\mathrm{MOE}_{\mathrm{TOF}}$ affected the predictive relationship between $\mathrm{MOE}_{\mathrm{TOF}}$ and $\mathrm{MOE}_{\mathrm{SS}}$. Regression models were compared using different combinations of $k$ and GD at the different levels to calculate tree-level estimates of $\mathrm{MOE}_{\mathrm{TOF}}$ and regressed these against tree-level $\mathrm{MOE}_{\mathrm{SS}}$. These were also compared with models in which plot-level or site-level MOE values were calculated from the same level of $k$ and GD. The fit of these models were evaluated using adjusted $\mathrm{R}^{2}$ and root mean square error (RMSE).

The assumptions of normality and homoscedasticity for these models were tested using graphical diagnostics (residual and QQ plots), and examined the residuals for high leverage data points ( $\mathrm{R}$ package car). Finding some departure from normality and homoscedasticity, several data transformations were tested but found that none of these had much effect; however, dropping four outlier data points eliminated the normality and variance issues. Therefore, subsequent analyses used untransformed data.

To identify predictor variables that might explain variation in MOE, we added to the models selected above additional variables that gave the optimal relationships between $\mathrm{MOE}_{\mathrm{TOF}}$ and $\mathrm{MOE}_{\mathrm{SS}}$ for each of tree, plot and site levels. Twelve forest inventory variables were tested in five categories: stand stocking, stand age, tree size, crown metrics, and competition (Table 2). These variables were moderately to strongly correlated with one or more of the other variables, especially with other variables within the same category. Therefore, an all-possible-subsets procedure ( $\mathrm{R}$ package leaps) was performed to determine regression models combining inventory covariates with the MOE variables that included no more than one inventory variable per category and avoided over-fitting the model. The best subset model was chosen based on minimization of the Cp statistic (Mallows 1973).

With the most significant inventory variables chosen, they were incorporated into a further model including them with
MOE and their interactions. We chose to use only 2-way interactions to limit the number of variables in the models to allow all-possible-subsets regression and to facilitate interpretation of the results.

The fit of the base model (MOE variable only) was compared with one including inventory main effects only, and with one including main effects and interactions. The models were evaluated based on maximizing the adjusted $\mathrm{R}^{2}$ and minimizing the Akaike Information Criterion (AIC; Akaike 1974) and Bayesian Information Criterion (BIC; Schwarz 1978). The fit of the resulting best model was tested by examining residuals for normality and homoscedasticity using graphical diagnostics.

To account for the hierarchical nature of the dataset, the $\mathrm{MOE}_{\mathrm{TOF}}$ prediction model was tested with the inclusion of random intercept effects at site, plot and tree level in the model. The model used the following model formulation (Laird and Ware 1982):

$$
\text { [6] } \mathbf{y}=\mathbf{X} \boldsymbol{\beta}+\mathrm{Z} \mathbf{u}+\boldsymbol{\varepsilon}
$$

Where $\mathbf{y}$ is the response vector, $\mathbf{X}$ and $\mathbf{Z}$ are matrices of the explanatory variables corresponding to fixed and random effects, respectively, $\boldsymbol{\beta}$ and $\mathbf{u}$ are the corresponding vectors of parameters for the respective fixed and random effects, and $\boldsymbol{\varepsilon}$ is a vector of random errors.

These models were evaluated using AIC, BIC and significance testing for differences among them using logLikelihood tests. The final mixed effects model was evaluated through examination of residuals and calculation of root mean square error (RMSE), \% bias, and mean absolute prediction error (MAPE).

The same process used above for tree-level data was followed for testing models using plot-level and site-level data.

\section{Results \\ Relationship between tree TOF and log resonance acoustic measurements}

Time-of-flight-based velocity values measured on individual standing lodgepole pine trees using the ST300 tool ranged from 3.59 to $5.22 \mathrm{~km} / \mathrm{s}$ across all sites and silvicultural treatments (Fig. 1). These were consistently higher than resonance-based values measured on the lower bole logs from those trees using the HM200 tool, which ranged from 3.19 to $4.24 \mathrm{~km} / \mathrm{s}$. The correlation between $\mathrm{V}_{\text {TOF }}$ and $\mathrm{V}_{\text {RES }}$ was 0.708 $(\mathrm{p}<0.0001)$.

The value of the adjustment factor $k$ to convert ToF measurements to resonance-equivalent values calculated for individual trees varied from 1.10 to 1.35 , with a mean population value of 1.24 (Fig. 2).

Predictions of SilviScan MOE from acoustic velocity-derived MOE MOE was calculated from $V_{\text {RES }}$ and GD measured on each $\log$. $\mathrm{MOE}_{\mathrm{RES}}$ was lower than MOE calculated from SilviScan analysis of wood samples taken from both ends of the lower $\log$ (Fig. 3). The ratio of $\mathrm{MOE}_{\mathrm{SS}}$ to the $\mathrm{MOE}$ estimated from acoustic velocity was consistently about 1.4 $\left(\mathrm{MOE}_{\mathrm{SS}} / \mathrm{MOE}_{\mathrm{TOF}}\right.$ mean=1.38, SE $=0.016 ; \mathrm{MOE}_{\mathrm{SS}} / \mathrm{MOE}_{\mathrm{RES}}$ mean $=1.40, \mathrm{SE}=0.010$ ). Regression of $\mathrm{MOE}_{\mathrm{RES}}$ on $\mathrm{MOE}_{\mathrm{SS}}$ showed a significant $(\mathrm{p}<0.001)$ and strong relationship (adjusted $\mathrm{R}^{2}=0.691$ ) between the two measures (Table 3). 


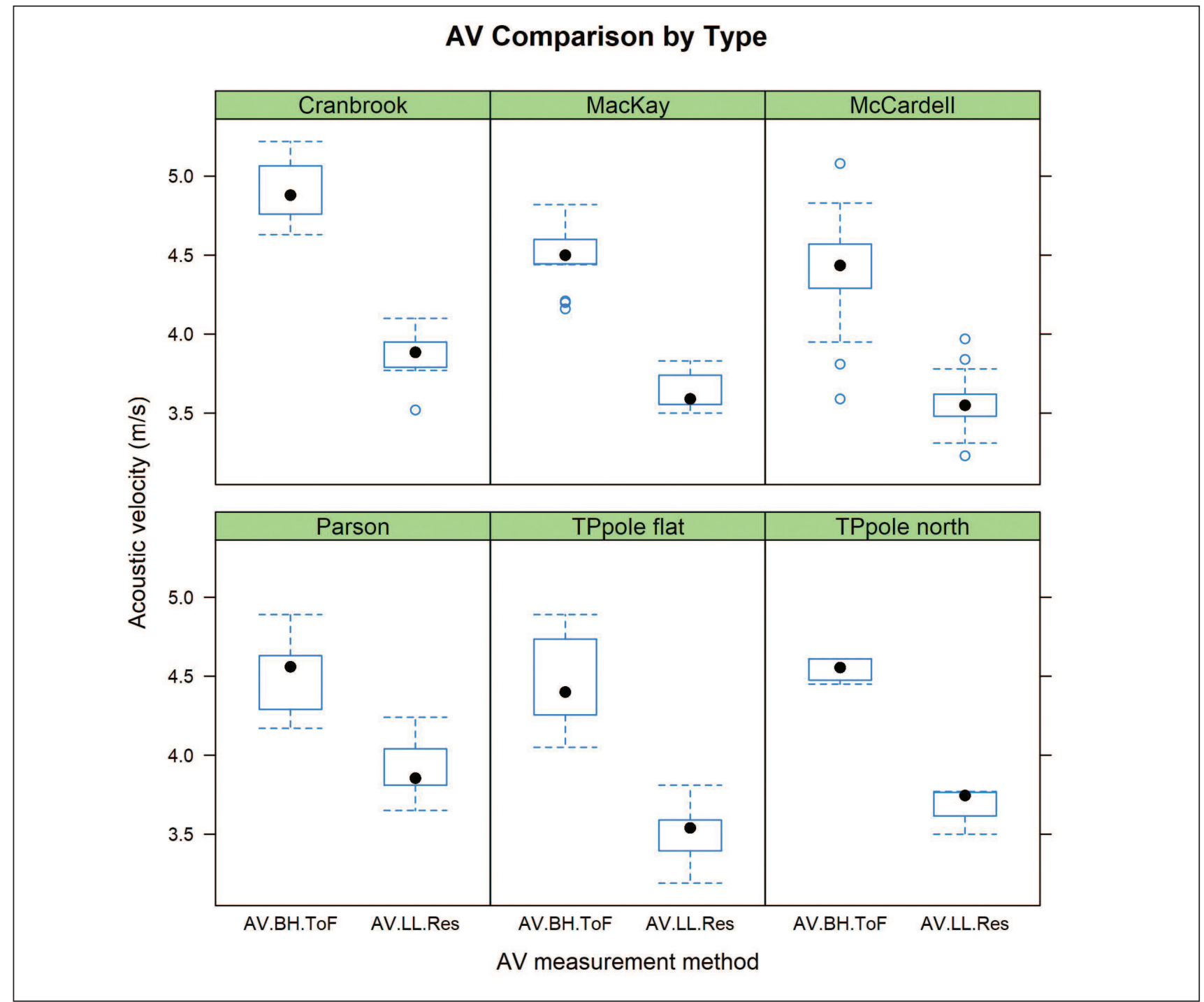

Fig. 1 Acoustic velocity (AV) measured at six different lodgepole pine sites as time-of-flight (TOF) at breast height (BH, $1.3 \mathrm{~m}$ ) on standing trees, and as resonance velocity (RES) on the lower log (LL) of the same trees. All treatments are pooled within each of the six sites.

MOE was calculated from standing tree AV measurements, adjusted using individual-tree $k$ and GD, and compared with SilviScan $\mathrm{MOE}_{\mathrm{SS}}$ averaged from wood samples taken at breast height $(1.3 \mathrm{~m})$, which corresponded most closely to the stem measurement position of the tree TOF tool. $\mathrm{MOE}_{\mathrm{TOF}}$ prediction of $\mathrm{MOE}_{\mathrm{SS}}$ was significant $(\mathrm{p}<0.0001)$ but not as strong (adjusted $\mathrm{R}^{2}=0.593$ ) as predictions from $\mathrm{MOE}_{\mathrm{RES}}$ (Table 3). Removing four outliers to meet the assumption of normality lowered the adjusted $\mathrm{R}^{2}$ to 0.587 but also reduced RMSE by $0.152 \mathrm{GPa}$.

MOE varied across the scales of the study. The variance component model showed that $80 \%$ of the variation in $\mathrm{MOE}$ occurred among trees within a plot, and $20 \%$ among sites (Table 4). There was no significant variation at the plot level.

\section{Effect of different scales of estimation of $k$ and GD}

The factor $k$ also varied most at the tree-level (50\%), but almost as much among sites (41 \%) (Table 4, Fig. 2A). Variation was least among plots within sites (9\%). To test the effect of using different spatial scales of mean $k$ to adjust $V_{\text {TOF }}$ mea- surements we used $k$ calculated at the plot-scale (mean $k$ of trees from each site-treatment combination), site-scale (mean $k$ of trees from all plots within each site), and population-scale (mean of the six site $k$ ). The correlation between $\mathrm{V}_{\mathrm{RES}}$ and adjusted $\mathrm{V}_{\mathrm{TOF}}$ increased as the value of $k$ was estimated at finer scales. Using the plot-level, site-level or population-level mean values of $k$ incrementally reduced the variation in $k$, but also increased the deviation from measured $\mathrm{V}_{\text {RES. }}$ (Fig. 4).

Tree-level $\mathrm{MOE}_{\mathrm{TOF}}$ calculated using values of $k$ averaged at the plot, site and population scales were regressed on $\mathrm{MOE}_{\mathrm{SS}}$ at breast height. Averaging $k$ at broader scales incrementally reduced the $\mathrm{R}^{2}$ from 0.59 for tree-level $k$, to 0.54 , 0.51 , and 0.48 for population-level $k$, as RMSE increased from 1.14 to $1.27 \mathrm{GPa}$ (Table 3).

Green density ranged from 652 to $889 \mathrm{~kg} / \mathrm{m}^{3}$ (Fig. 2B) and was more variable (higher coefficient of variation) among trees within plots (69\% of total variance) than among plots within sites (5\%) or among sites (26\%) (Table 4). Averaging $\mathrm{GD}$ at incrementally broader scales reduced the $\mathrm{R}^{2}$ of the 
A

$\mathrm{MOE}_{\mathrm{TOF}}-\mathrm{MOE}_{\mathrm{SS}}$ regression from 0.59 for tree-level GD, to $0.42,0.39$ and 0.31 for population-level GD (Table 3) and increased RMSE from 1.135 to $1.466 \mathrm{GPa}$.

The results of calculating $\mathrm{MOE}_{\mathrm{TOF}}$ at plot and site levels were also examined using the corresponding levels of average $k$ and GD. At the plot level, $\mathrm{R}^{2}$ was 0.80 and RMSE 0.437; at site level these were 0.81 and 0.296 , respectively (Table 3 ).

\section{Addition of forest inventory variables}

Adding all inventory variables to the tree-level MOE regression (using both $k$ and GD at tree-level for estimating $\mathrm{MOE}_{\mathrm{TOF}}$ ) produced a model with severe multicollinearity. Applying the subset selection process identified a four-variable model as optimum (lowest $\mathrm{Cp}$ value). This main effects model included SDI50, DBH and Ht2LC in addition to $\mathrm{MOE}_{\mathrm{TOF}}$, and reduced AIC from 284 for the MOE-only model to 279 (Table 5). In the next step, two-way interactions were allowed into the model. Now the $\mathrm{Cp}$ index indicated a four-variable model including $\mathrm{MOE}_{\mathrm{TOF}}, \mathrm{MOE}_{\mathrm{TOF}} \times \mathrm{Ht} 2 \mathrm{LC}$, SDI50 $\times$ Trt_age, and SDI50 $\times$ DBH. However, adding interactions increased AIC to 283. Adding inventory variables to the plot- and site-level regressions did not result in improved fit so they were not included going forward.

\section{Testing random effects}

Random effects were added to the above models to account for the hierarchical structure of the data. For the tree-level model, adding a random intercept for site or for plot nested in site did not result in a significant difference (likelihood tests p-values $>0.1$ ) and gave higher AIC and BIC values
B

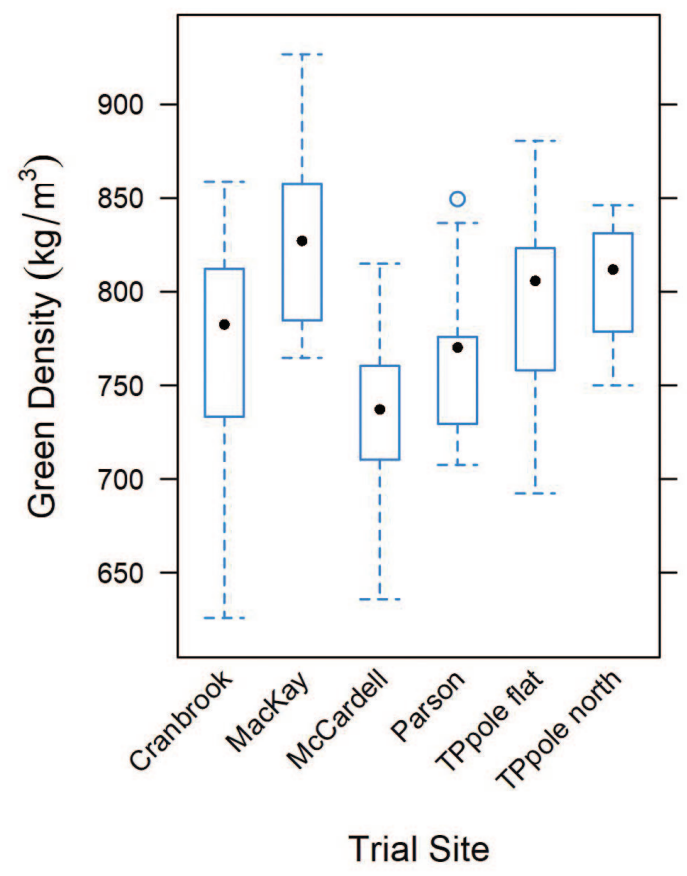

(Table 6). Therefore, we remained with the fixed-effects only model at this scale. At the plot-level, adding a random intercept for site resulted in a marginally significant difference in the likelihood test against the fixed-effect only model (Table 6). However, AIC and BIC were lower in the mixed model, so we chose to use the latter.

\section{Final models}

The final tree-level four-variable model had an $\mathrm{R}^{2}=0.662$ and RMSE $=1.0665$, but with a high bias and mean absolute prediction error (MAPE) (Table 7). The final models for both plot- and site-levels had higher $\mathrm{R}^{2}$ by about $20 \%$, about onethird the RMSE and MAPE, and about one-tenth the \% bias. Graphical diagnostics validated our assumptions of normality and homogeneity of variance for residuals in all models.

\section{Discussion}

\section{Acoustic velocity measurements}

$\mathrm{V}_{\mathrm{TOF}}$ was a moderately good predictor of $\mathrm{V}_{\mathrm{RES}}$ in the lower $\log \left(\mathrm{R}^{2}=0.50\right)$, the log section corresponding to the location where $\mathrm{V}_{\mathrm{TOF}}$ was measured, with an obvious bias upward (Fig. 1). Relationships of similar strength between unadjusted tree TOF and log resonance measurements have been reported for western hemlock (Tsuga heterophylla (Raf.) Sarg.), Sitka spruce (Picea sitchensis (Bong.) Carr.) (Wang and Ross 2008), and Abies amabilis Douglas ex J. Forbes (Middleton and Munro 2013).

The higher acoustic velocity measured in standing trees compared with that in logs is due to inherent differences in stem measurement location and stress wave propagation 


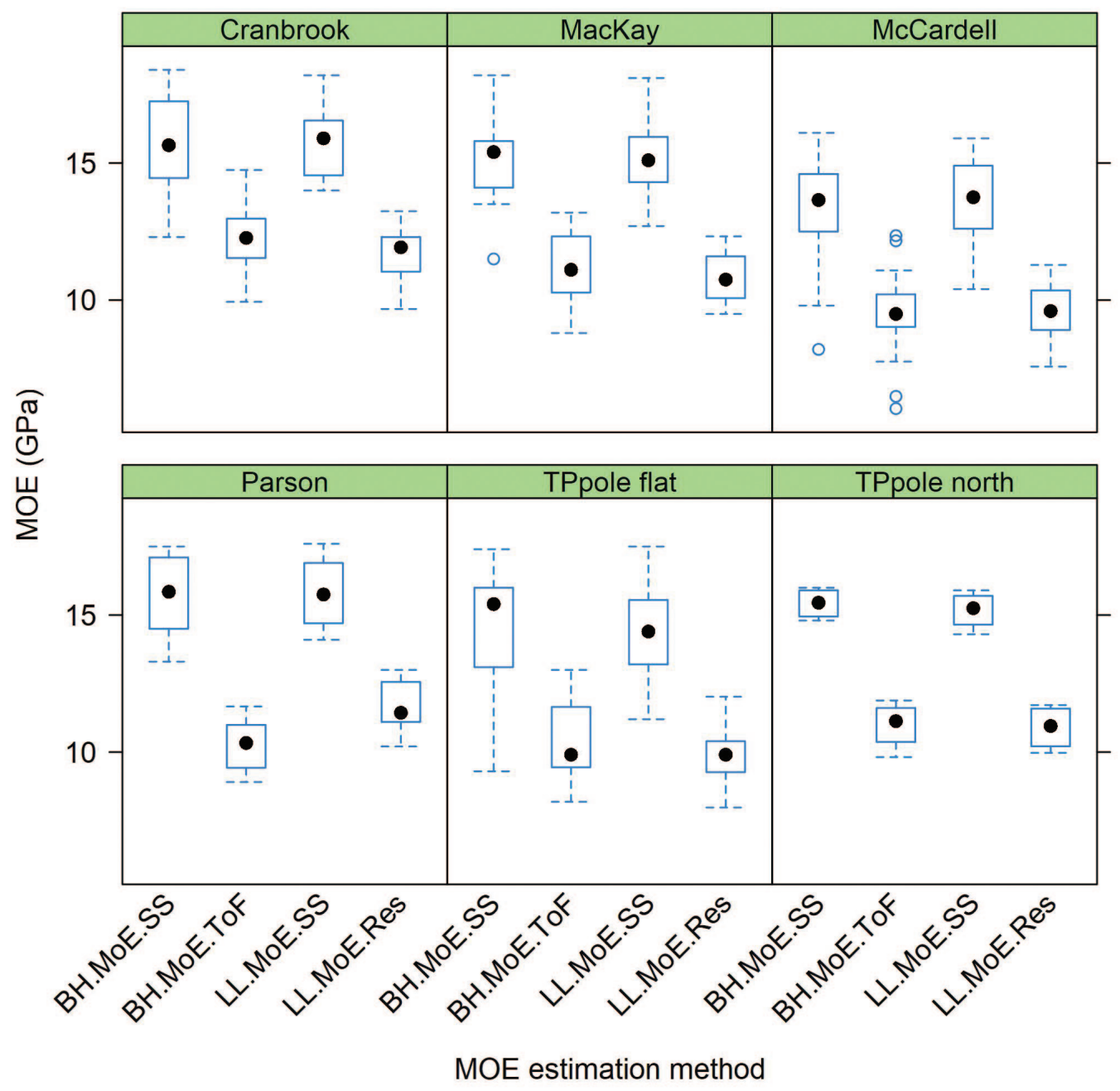

Fig. 3 Modulus of Elasticity estimated at six different lodgepole pine sites from SilviScan (SS) and acoustic velocity measurements, either time-of-flight (ToF) at $1.3 \mathrm{~m}(\mathrm{BH})$ on standing trees or resonance measurements (Res) on the lowest log (LL).

between the two acoustic tools. The shallow sensor penetration of the TOF tools produces velocity measurements presumed to be predominately through mature outerwood (Grabianowski et al. 2006). Although deviation between tree $\mathrm{V}_{\mathrm{TOF}}$ and $\log \mathrm{V}_{\mathrm{RES}}$ seems to be linked to high stiffness in the outerwood layers, the fundamental cause of this deviation stems from the difference in the wave propagation mechanism, dilatational-dominated wave (i.e. time-of-flight) and one-dimensional plane (i.e., resonance) wave respectively, between the two acoustic tools (Legg and Bradley 2016).

Bark can also contribute to lower resonance velocity in logs compared to TOF-based velocity in trees because it adds to the log volume (log acoustic tools use volume-averaged resonance) while contributing little to stiffness, whereas it is not a factor with tree TOF acoustic tools using probes that penetrate the bark into the sapwood. While the effect of bark on $\log$ acoustic velocity was not determined in this study, bark was reported to decrease acoustic velocity in logs by 4.1 $\%$ in radiata pine (Lasserre et al. 2007) and $4.6 \%$ in Douglasfir (Pseudotsuga menziesii (Mirb.) Franco) (Murphy and Amishev 2008), indicating a relatively small effect compared with the differences attributed to stress wave propagation between TOF-based and resonance-based tools.

\section{Estimation of tree-level MOE}

The mean $\mathrm{MOE}_{\mathrm{RES}}(10.56 \mathrm{GPa})$ in lower logs was much lower than the corresponding mean SilviScan $\mathrm{MOE}_{\mathrm{SS}}$ values (14.74 GPa). In a mill study of a different subset of trees at the same Cranbrook site as in the present study, Mortyn et al. (2015) found the average $\mathrm{MOE}_{\mathrm{RES}}$ for lower logs $(11.6 \mathrm{GPa}$ ) was similarly lower than the corresponding mean $\mathrm{MOE}_{\mathrm{SS}}$ value $(15.9 \mathrm{GPa})$. The $\mathrm{R}^{2}$ for the relationship between $\mathrm{MOE}_{\mathrm{RES}}$ and SilviScan $\mathrm{MOE}_{\mathrm{SS}}$ in the lower logs was 0.691 (Table 3).

The mean $\mathrm{V}_{\mathrm{TOF}} / \mathrm{V}_{\mathrm{RES}}$ ratio, $k$, observed for lodgepole pine (1.24) is within the range of 1.07 to 1.36 reported for several other conifer species (Wang et al. 2007; Mora et al. 2009). The HM200 and ST300 instruments differ in the entities that they measure (logs $v s$. trees) and their mode of measurement (resonance $v s$. time-of-flight), therefore it is to be expected that the different characteristics of trees and stands might affect the measurements from the two instruments in different ways. The extent to which the measurements from the two 
Table 3. Results from linear regression of tree-level MOE (GPa) estimated from acoustic velocity measurements on MOE measured using Silviscan on trees and logs of lodgepole pine

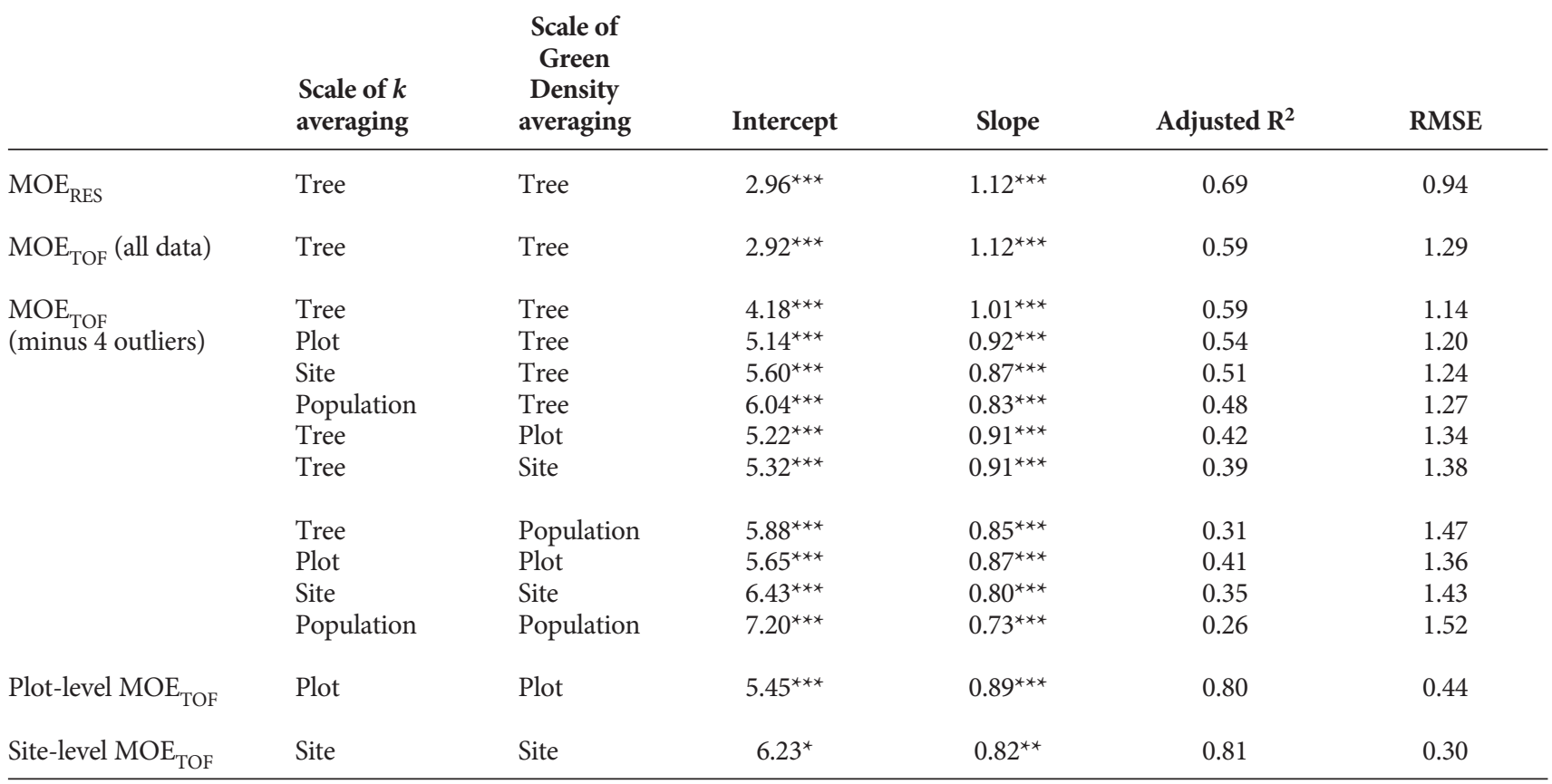

Note: significance levels of model parameters: ${ }^{*} \mathrm{p} \leq 0.05,{ }^{* *} \mathrm{p} \leq 0.005,{ }^{* * *} \mathrm{p} \leq 0.0005$

instruments are differentially affected will determine the variation of $k$ among trees and stands. Since half of the variation observed in $k$ was due to differences among trees, it is not surprising that values of $k$ averaged at plot or site level did not give good estimates of $\mathrm{MOE}$ at the tree level.

In this study, $\mathrm{V}_{\mathrm{TOF}}$ values were more variable than $\mathrm{V}_{\mathrm{RES}}$ values (Fig. 1), which was also reflected in $\mathrm{MOE}_{\mathrm{TOF}}$ being more variable than $\mathrm{MOE}_{\mathrm{RES}}$ (Fig. 3). However, $\mathrm{MOE}_{\mathrm{TOF}}$ (using adjusted $\mathrm{V}_{\mathrm{TOF}}$ ) was closely related to lower log $\mathrm{MOE}_{\mathrm{RES}}\left(\mathrm{R}^{2}=0.82\right)$. Other studies have reported moderate (Raymond et al. 2008) to strong (Lasserre et al. 2007) correlations between standing tree and lower log MOE using TOFbased and resonance-based acoustic tools, respectively. Moderate (Chauhan and Walker 2006) to strong (Mora et al. 2009) predictive relationships have been reported between $\mathrm{V}_{\mathrm{TOF}}$ or $\mathrm{MOE}_{\mathrm{TOF}}$ and $\mathrm{MOE}_{\mathrm{SS}}$.

Although $\mathrm{AV}$ is the greatest determinant of $\mathrm{MOE}$, in that the AV value is squared in the calculation, part of the variation in $\mathrm{MOE}_{\mathrm{RES}}$ also comes from variation in GD. In this study, GD ranged from 652 to $889 \mathrm{~kg} / \mathrm{m}^{3}$, higher than previous reports for lodgepole pine, but similar to other related pines (Miles and Smith 2009). Our GD coefficient of variation (CV) (6.4) was similar to those of $\mathrm{AV}_{\mathrm{RES}}$ and $\mathrm{AV}_{\mathrm{TOF}}(5.8$ and 6.7 , respectively), but was not significantly correlated with either, nor with $k$. Green density was moderately correlated with $\mathrm{MOE}(\mathrm{r}=0.50)$, as expected since GD was used to calculate MOE.

Moisture content affects wood stiffness, with higher $\mathrm{MOE}_{\mathrm{SS}}$ values related to lower moisture content. AV was measured on green wood above the fibre saturation point (FSP) $(28-30 \% \mathrm{MC})$, whereas SilvisScan measured wood samples conditioned to $8 \%$ MC. This difference could account for the $10-20 \%$ increase in $\mathrm{MOE}_{\mathrm{SS}}$ compared to green logs and trees due to the inverse linear relationship between moisture content below the FSP and acoustic velocity or MOE (Gerhards 1982).

The clear straight-grained wood of SilviScan samples may also have contributed to higher $\mathrm{MOE}_{\mathrm{SS}}$ values compared to $\mathrm{MOE}_{\mathrm{RES}}$ (and $\mathrm{MOE}_{\mathrm{TOF}}$ ) measurements. $\mathrm{MOE}_{\mathrm{RES}}$ measurements represent the entire log volume, including knots, compression wood, internal checks and other defects that can lower MOE. The size and location of defects determines the grade limiting point (lowest MOE in static bending tests) for lumber. These defects would not be represented by the clear wood samples used in SilviScan analysis. SilviScan analysis also excluded the bark, which would account for a small additional increase in MOE over that of unprocessed logs.

\section{Tree vs. stand estimates of MOE}

As expected, regression using stand-level means for both response (MOE) and explanatory variables corresponding to each treatment plot $(n=20)$ or site $(n=6)$ resulted in stronger $\mathrm{MOE}_{\mathrm{TOF}}$ predictions of $\mathrm{MOE}_{\mathrm{SS}}\left(\mathrm{R}^{2}=0.80\right.$ and 0.81 , respectively) than when using individual tree values $\left(R^{2}=0.59\right)$. These results indicate that TOF tools may be best suited for providing reliable stand-average estimates of wood mechanical properties for pre-harvest screening to identify stands potentially meeting grade criteria for high-stiffness structural lumber and LVL products. Moore et al. (2013) reported a similar strong relationship in Sitka spruce $\left(\mathrm{R}^{2}=0.83\right)$ between stand-level means of MOE using a TOF acoustic tool and lumber MOE from bending tests. In that study, the strong 
Table 4. Percent of total variation in $\mathrm{MOE}_{\mathrm{SS}}, \mathrm{k}$ and green density attributed to spatial scales of organization (stand, plot, residual]

\begin{tabular}{lccc}
\hline Variable & $\begin{array}{c}\text { Between } \\
\text { Stands }\end{array}$ & $\begin{array}{c}\text { Between Plots } \\
\text { Within Stand }\end{array}$ & Residual \\
\hline MOE $_{\mathrm{SS}}$ (lower log) & 20.0 & $<0.00$ & 80.0 \\
$k$ & 41.4 & 9.1 & 49.5 \\
green density & 26.4 & 5.0 & 68.6 \\
\hline
\end{tabular}

predictive relationship obtained using stand-level means was tempered by their finding that most of the variation (75\%) in lumber MOE occurred within stands, which included MOE variation within trees and logs comparable to our observation that $80 \%$ of the variation in MOE was attributed to tree within plots (Table 4), the remainder of the variation being attributed to differences among sites (Table 4). These results support the suggestion by Paradis et al. (2013) that standing tree TOF tools could be integrated into forest surveys to obtain low-cost stand-level MOE estimates to help inform stand selection decisions directed towards meeting current mill requirements for specific MSR lumber grades. However, further information on MOE might be needed from resonance measurements on logs during harvest or during sorting in the mill yard to account for the large within-site variation in MOE.

The $\mathrm{R}^{2}$ change from a model using tree-level GD to one using plot-level average was from 0.59 to 0.42 (Table 3), which was a greater effect than that in using different scales for average $k$. Given this result and the within-site variation in GD we conclude that individual tree GD measurements provide the most accurate estimates of tree-level MOE. Todoroki and Lowell (2016) came to a similar conclusion in their study of acoustic velocity modelling for Douglas-fir (Pseudotsuga menziesii).

\section{Influence of forest inventory variables}

Estimation of tree-level MOE from acoustic measurements could be improved by including information on tree size $(\mathrm{DBH})$ and structure (Ht2LC), and stand-level stocking (SDI50) (Table 7). However, with $\mathrm{MOE}_{\mathrm{TOF}}$ as the predictor variable in the model, the inventory variables contributed only $3.6 \%$ to the $\mathrm{R}^{2}$ (Table 5). Merlo et al. (2014) also tested the addition of easily available forest inventory variables to models predicting MOE from $\mathrm{V}_{\mathrm{TOF}}$ for Pinus pinaster (Ait.), resulting in a stand-level model including only SI as an inventory variable $\left(\mathrm{R}^{2}=0.89\right)$, and a tree-level model including $\mathrm{BAL}, \mathrm{BA} / \mathrm{ha}, \mathrm{SI}$ and $\mathrm{DBH}$ as predictors $\left(\mathrm{R}^{2}=0.69\right)$. Tree size variables were found to provide small but significant improvements in prediction of MOE from $\mathrm{V}_{\mathrm{TOF}}$ in Douglasfir, adding from $2 \%$ to $8 \%$ to the $\mathrm{R}^{2}$, with stem slenderness (HDR) giving slightly better results than $\mathrm{DBH}$ or tree height, either alone or in combination (Todoroki and Lowell 2016).

\section{Relationship of dynamic MOE estimates to MOE from static} bending tests

Measurement of dynamic MOE using acoustic tools generally gives MOE values 5-11\% higher than those from static bending tests (Raymond et al. 2007). The relationships we observed between MOE estimated from acoustic velocity and SilviScan are also in general agreement with reported strong relationships $\left(\mathrm{R}^{2}=0.62-0.94\right)$ between resonance-based

Table 5. Comparison of different tree-level fixed effects models; all models were significant at $p<0.0001$

\begin{tabular}{lcccc}
\hline Model & adj. $\mathbf{R}^{2}$ & $\begin{array}{c}\text { sigma } \\
\text { (variance) }\end{array}$ & AIC & BIC \\
\hline MOE only (no covariates) & 0.586 & 1.15 & 284 & 292 \\
+ inventory variables & 0.622 & 1.10 & 279 & 294 \\
+ interactions & 0.619 & 1.10 & 283 & 308 \\
\hline
\end{tabular}
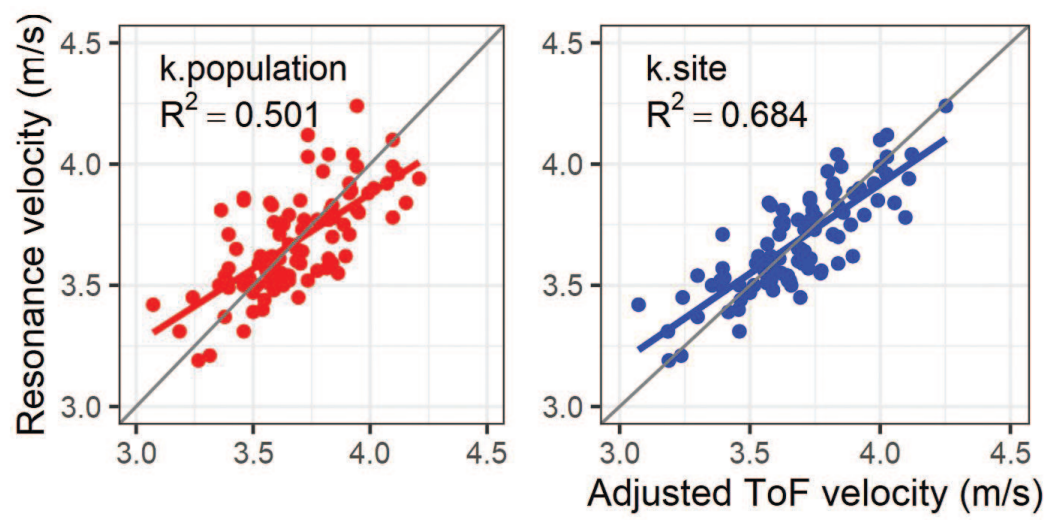

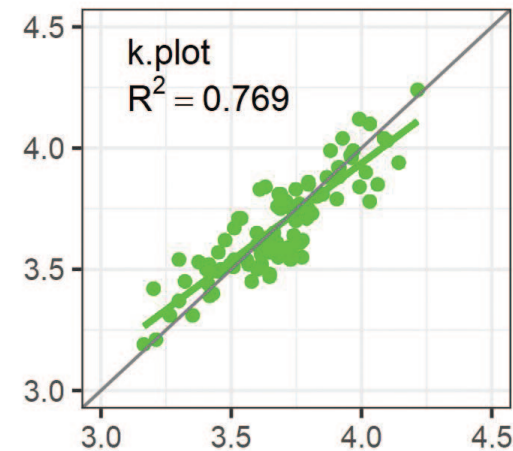

Fig. 4 Comparison of different scales of averaging the $k$ adjustment factor on the relationship between resonance acoustic velocity and adjusted time-of-flight (ToF) acoustic velocity. The least squares regression line and adjusted $\mathrm{R}^{2}$ are indicated for each dataset, as well as the $1: 1$ line (i.e., individual tree $k$ values used for adjustment). 
Table 6. Comparison of different random effects with final tree-level fixed effects model; differences between model formulations were tested for significance using logLiklihood ratio tests

\begin{tabular}{|c|c|c|c|c|c|c|c|}
\hline Model & DF & AIC & BIC & logLiklihood & test & $\begin{array}{l}\text { Liklihood ratio } \\
\quad(p \text {-value })\end{array}$ & Significance \\
\hline \multicolumn{8}{|l|}{ Tree-level models } \\
\hline Fixed only & 6 & 308 & 322 & -147.814 & & & \\
\hline + Random Site & 7 & 310 & 327 & -147.725 & 1 vs. 2 & 0.177 & 0.67 \\
\hline + Random Site/Plot & 8 & 312 & 331 & -147.725 & 2 vs. 3 & $5 \times 10^{-8}$ & 1.00 \\
\hline \multicolumn{8}{|l|}{ Plot-level models } \\
\hline Fixed only & 3 & 35.2 & 37.9 & -14.590 & & & \\
\hline + Random Site & 4 & 33.5 & 37.0 & -12.730 & 1 vs. 2 & 3.72 & 0.054 \\
\hline
\end{tabular}

Table 7. Results from linear regression of plot- and site-level MOE estimated from average acoustic velocity measurements on average MOE measured using SilviScan on lodgepole pine trees; model terms were tested for significance using twosided t-tests

\begin{tabular}{|c|c|c|c|c|}
\hline & $\begin{array}{l}\text { Parameter } \\
\text { estimate }\end{array}$ & Std Error & t-value & $\begin{array}{c}\text { Signifi- } \\
\text { cance } \\
\text { (p-value) }\end{array}$ \\
\hline \multicolumn{5}{|l|}{ Tree-level, fixed } \\
\hline Intercept & 2.25 & 1.20 & 1.86 & $0.0657+$ \\
\hline $\mathrm{MOE}_{\mathrm{TOF}}(\mathrm{GPa})$ & 1.16 & 0.102 & 11.3 & $<2 \mathrm{e}-16^{* * *}$ \\
\hline SDI50 & 0.00107 & 0.000452 & 2.38 & $0.0197^{\star}$ \\
\hline $\mathrm{Dbh}(\mathrm{cm})$ & 0.0945 & 0.0381 & 2.48 & $0.0151 *$ \\
\hline $\mathrm{Ht} 2 \mathrm{LC}(\mathrm{m})$ & -0.175 & 0.0566 & -3.09 & $0.00272^{\star *}$ \\
\hline Res. Std. Error & - & 1.10 & $85 \mathrm{DF}$ & - \\
\hline Adjusted $\mathrm{R}^{2}$ & 0.622 & - & - & - \\
\hline RMSE & 1.07 & - & - & - \\
\hline$\%$ bias & -0.550 & - & - & - \\
\hline $\begin{array}{l}\text { Mean absolute } \\
\text { prediction error }\end{array}$ & 5.89 & - & - & - \\
\hline \multicolumn{5}{|l|}{ Plot-level, mixed } \\
\hline Intercept & 6.75 & 6.75 & 4.93 & $3 e-04^{* * *}$ \\
\hline $\mathrm{MOE}_{\mathrm{TOF}}(\mathrm{GPa})$ & 0.775 & 0.127 & 6.10 & $0 \mathrm{e}+00^{* * *}$ \\
\hline Random Site & - & 0.315 & - & - \\
\hline Residual & - & 0.360 & - & - \\
\hline Adjusted $\mathrm{R}^{2}$ & & & & \\
\hline $\begin{array}{l}\text { (fixed effects only) } \\
\text { RMSE }\end{array}$ & $\begin{array}{l}0.803 \\
0.390\end{array}$ & $\begin{array}{l}- \\
-\end{array}$ & $\begin{array}{l}- \\
-\end{array}$ & $\begin{array}{l}- \\
-\end{array}$ \\
\hline$\%$ bias & -0.0558 & - & - & - \\
\hline $\begin{array}{l}\text { Mean absolute } \\
\text { prediction error }\end{array}$ & 1.74 & - & - & - \\
\hline \multicolumn{5}{|l|}{ Site-level, fixed } \\
\hline Intercept & 6.23 & 1.88 & 3.32 & $0.0295^{\star}$ \\
\hline $\mathrm{MOE}_{\mathrm{TOF}}(\mathrm{GPa})$ & 0.824 & 0.174 & 4.74 & 0.00902 ** \\
\hline Res. Std. Error & - & 0.362 & $4 \mathrm{DF}$ & - \\
\hline Adjusted $\mathrm{R}^{2}$ & 0.811 & - & - & - \\
\hline RMSE & 0.296 & - & - & - \\
\hline$\%$ bias & -0.0431 & - & - & - \\
\hline $\begin{array}{l}\text { Mean absolute } \\
\text { prediction error }\end{array}$ & 1.78 & - & - & - \\
\hline
\end{tabular}

Note: significance levels of model parameters: $+\mathrm{p} \leq 0.1,{ }^{*} \mathrm{p} \leq 0.05,{ }^{* *} \mathrm{p} \leq 0.005,{ }^{* * *}$ $\mathrm{p} \leq 0.0005$
MOE and MOE from static bending of lumber from black spruce and balsam fir (Duchesne 2009), Douglas-fir (Cherry et al. 2008) and Sitka spruce (Moore et al. 2013). In a post-hoc mill study of the silvicultural treatments at the Cranbrook site, the average static bending MOE of dry lumber (11.4 $\mathrm{GPa}$ ) was in close agreement with the average $\mathrm{MOE}_{\mathrm{RES}}$ value (11.6 GPa) for lower logs (and $\mathrm{MOE}_{\mathrm{TOF}}$ in trees) from the same site as in the present study, but was considerably lower than the corresponding mean SilviScan $\mathrm{MOE}_{\mathrm{SS}}$ value (15.9 GPa) (Mortyn et al. 2015). Similarly, the average value for static bending MOE (10.9 GPa) of clear samples of dry lodgepole pine wood from untreated Canadian stands (Kretschmann 2010) was identical to the mean $\mathrm{MOE}_{\mathrm{RES}}(10.9$ $\mathrm{GPa}$ ) in lower logs from untreated stands in the present study, but again was much lower than corresponding mean SilviScan $\mathrm{MOE}_{\mathrm{SS}}$ values (15.3 GPa).

SilviScan calculates dynamic MOE from a model whose calibration constants were estimated from sonic testing (Evans 2006), and also produces higher values of MOE than static bending tests even when controlling for moisture content (Raymond et al. 2007). SilviScan wood samples were conditioned to $8 \% \mathrm{MC}$, whereas static bending tests are usually performed on wood at $12-15 \%$ MC.

\section{Operational considerations}

The resonance-based tool provides reliable estimates of SilviScan-analysed wood mechanical properties and highly repeatable and rapid measurements, which is why these tools have been widely implemented for sorting logs into stiffness grades. Although $\mathrm{MOE}_{\mathrm{RES}}$ was a stronger predictor of SilviScan-analysed $\mathrm{MOE}_{\mathrm{SS}}$ than was $\mathrm{MOE}_{\mathrm{TOF}}, \mathrm{MOE}_{\mathrm{TOF}}$ was well correlated with $\mathrm{MOE}_{\mathrm{SS}}$ in the lower log, which corresponds closely to the breast height measurement position of the tree TOF tool.

Significantly stronger predictions of wood stiffness were obtained with both acoustic tools when regressions were based on stand-level means (corresponding to each treatment plot) of predictor $\left(\mathrm{V}_{\mathrm{TOF}}\right.$ and $\left.\mathrm{V}_{\mathrm{RES}}\right)$ and response $\left(\mathrm{MOE}_{\mathrm{SS}}\right)$ variables, compared to using regression models based on individual tree or log data. The inherently higher measurement variability of TOF tools (compared with resonance-based tools) makes them more suitable for stand-level estimates than for tree-level estimates of wood mechanical properties for pre-harvest assessment. Although only one fifth of the variation in MOE in this study was attributed to differences between stands, the use of TOF tools can be used 
to rank stands of differing wood quality. Aggregate standlevel wood quality information can inform stand selection decisions; for example, to estimate how well overall stand wood stiffness would meet grade criteria set according to mill requirements for structural lumber and LVL. Unlike the operational potential for stand average estimates of $\mathrm{MOE}_{\mathrm{TOF}}$, stand average estimates of log wood quality $\left(\mathrm{MOE}_{\mathrm{RES}}\right)$ in forest inventories may be of limited use. Most applications of log acoustic tools and automated mill-based systems that measure stress wave velocity are for the purpose of grading and segregation of individual logs, which is more likely to occur in the millyard or on the sawline.

More reliable estimates of mechanical wood properties using TOF tools at the stand level does not preclude a potential role for TOF tools in ranking of individual trees, for the purpose of segregating low-stiffness material prior to harvest (Murphy and Cown 2015) or for screening for wood stiffness in tree improvement programs (Fundova et al. 2019). Timeof-flight measurements alone can be used for broadly ranking the relative stiffness among trees, provided there is adequate sampling around the stem. Standing tree TOF tool measurements can be performed quickly (about 1 minute per measurement position) and could be integrated into forest inventory surveys at a lower cost than methods requiring destructive sampling and lab analysis.

\section{Conclusions}

Acoustic velocity measured using time-of-flight on standing trees is higher than that using resonance on the lower logs of those trees; however, the two measures are well correlated and $\mathrm{V}_{\mathrm{TOF}}$ can be adjusted to $\mathrm{V}_{\mathrm{RES}}$ values using a simple factor, $k$. When combined with GD, the AV values (squared) are good predictors of MOE as measured by SilviScan. Variation in each of the variables, MOE, $k$ and GD, was greatest among trees within plots, which requires measurements at tree-level to make robust tree-level predictions of MOE.

Acoustic velocity measurements can provide useful estimates of MOE in standing trees; the models have modest explanatory power $\left(\mathrm{R}^{2}\right.$ ca. 0.6$)$ but require labour-intensive measurements of AV and GD on each tree. Estimating standlevel average MOE using stand-level values of AV, $k$ and GD avoids having to deal with the high variation among trees in each of these variables, and results in models with $\mathrm{R}^{2}>0.8$. Using available forest inventory variables to improve the tree-level prediction models increased the explanatory power by a few percent. Inventory variables were not found to significantly improve plot- or site-level models.

Acoustic tools can provide rapid, highly repeatable, reliable measurements and robust estimates of wood stiffness in both standing trees and logs. This information can be useful in sorting logs into stiffness grades before processing, in providing wood property information at the tree or stand level in forest inventories for operational or strategic planning, or in rapid screening for wood quality traits in a tree improvement program.

\section{Acknowledgements}

Funding for this study was provided by the Canadian Wood Fibre Centre of the Canadian Forest Service, Natural Resources Canada. The authors would like to acknowledge the very capable field and laboratory work provided by Jared Salvail, John Vallentgoed and Dominique Lejour. We also thank Alexis Achim, Isabelle Duchesne, and John Moore for constructive reviews of an earlier draft of this manuscript.

Antoine, Jim, and Roger would like to acknowledge the dedication and effort that Ross put into this project before his passing. Ross was a great colleague and friend and is dearly missed. His warm personality and calm demeanor made it very easy and pleasant to work with him.

\section{References}

Akaike, H. 1974. New look at statistical-model identification. IEEE Transactions on Automatic Control AC19:716-723.

Andrews, M.K. 2003. Which acoustic speed? In: F. C. Beall, (Ed.) Forest Products Society, Madison, Wisconsin.

ASTM International. 2017. ASTM D2395-17, standard test methods for density and specific gravity (relative density) of wood and woodbased materials. In: Section 9. TestMethodB-Volumeby Water Immersion American Society for Test West Conshohocken, PA.

Auty, D. and A. Achim. 2008. The relationship between standing tree acoustic assessment and timber quality in Scots pine and the practical implications for assessing timber quality from naturally regenerated stands. Forestry 81(4): 475-487. DOI 10.1093/forestry/ cpn015.

Carter, P., S. Chauhan and J. Walker. 2006. Sorting logs and lumber for stiffness using Director HM200. Wood Fiber Sci. 38(1): 49-54.

Chauhan, S.S. and J.C.F. Walker. 2006. Variations in acoustic velocity and density with age, and their interrelationships in radiata pine. For. Ecol. Manage. 229(1-3): 388-394. DOI http://dx.doi.org/ 10.1016/j.foreco.2006.04.019.

Cherry, M.L., V. Vikram, D. Briggs, D.W. Cress and G.T. Howe. 2008. Genetic variation in direct and indirect measures of wood stiffness in coastal Douglas-fir. Can. J. For. Res. 38(9): 2476-2486. DOI 10.1139/X08-087.

Duchesne, I. 2009. Assessment of Newfoundland's Wood Quality Using Acoustic Technology (Director HM200). Technical report, Project TT.5.02 No. 201000427. FPInnovations - Forintek, Quebec City, QC.

Edlund, J., H. Lindström, F. Nilsson and M. Reale. 2006. Modulus of elasticity of Norway spruce saw logs vs. structural lumber grade. Holz als Roh - und Werkstoff 64(4): 273-279. DOI 10.1007/s00107005-0091-7.

Evans, R. 2006. Wood stiffness by x-ray diffractometry. In: Characterisation of the cellulosic cell wall; D. Stokke and L. H. Groom, (Eds.). Wiley-Blackwell, Ames. Iowa, USA: pp: 138-146.

Filipescu, C.N., J.A. Trofymow and R.S. Koppenaal. 2016. Laterotation nitrogen fertilization of Douglas-fir: Growth response and fibre properties. Can. J. For. Res. 47(1): 134-138. DOI 10.1139/cjfr2016-0306.

Filipescu, C.N., M.U. Stoehr and D.R. Pigott. 2018. Variation of lumber properties in genetically improved full-sib families of Douglas-fir in British Columbia, Canada. Forestry: An International Journal of Forest Research 91(3): 320-326. DOI 10.1093/forestry/ cpy011.

Fischer, C., G.I. Vestøl, A. Øvrum and O.A. Høibø. 2015. Presorting of Norway spruce structural timber using acoustic measurements combined with site-, tree- and log characteristics. Eur. J. Wood Prod., 73(6): 819-828. DOI 10.1007/s00107-015-0946-5.

Fundova, I., T. Funda and H.X. Wu. 2019. Non-destructive assessment of wood stiffness in Scots pine (Pinus sylvestris L.) and its use in forest tree improvement Forests 10(6): 491. DOI 10.3390/ f10060491

Gerhards, C. 1982. Effect of moisture content and temperature on the mechanical properties of wood: An analysis of immediate effects. Wood Fiber Sci. 14(1): 4-36. 
Grabianowski, M., B. Manley and J.C.F. Walker. 2006. Acoustic measurements on standing trees, logs and green lumber. Wood Sci. Technol. 40(3): 205-216. DOI 10.1007/s00226-005-0038-5.

Huang, C.L., H. Lindström, R. Nakada and J. Ralston. 2003. Cell wall structure and wood properties determined by acoustics - a selective review. Holz als Roh - und Werkstoff 61(5): 321-335. DOI 10.1007/s00107-003-0398-1.

Jozsa, L.A. and G.R. Middleton. 1994. A discussion of wood quality attributes and their practical implications. In: Special Report. Forintek Canada Corp., Vancouver, Canada. 42 p.

Koch, P. 1996. Lodgepole Pine in North America. Madison WI: Forest Products Society.

Krajnc, L., N. Farrelly and A.M. Harte. 2019. The effect of thinning on mechanical properties of Douglas fir, Norway spruce, and Sitka spruce. Ann. Forest Sci. 76(1): 3. DOI 10.1007/s13595-018-0787-6. Kretschmann, D.E. 2010. Mechanical properties of wood. In: R. J. Ross, (Ed.). Wood Handbook, Wood as an Engineering Material, USDA Forest Service, Forest Products Laboratory, Madison, Wisconsin, USA: pp: 501-546.

Lachenbruch, B., G.R. Johnson, G.M. Downes and R. Evans. 2010. Relationships of density, microfibril angle, and sound velocity with stiffness and strength in mature wood of Douglas-fir. Can. J. For. Res. 40(1): 55-64. DOI 10.1139/x09-174.

Laird, N.M., and J.H. Ware. 1982. Random effects models for longitudinal data. Biometrics 38: 963-974. doi:10.2307/2529876

Lasserre, J.-P., E.G. Mason and M.S. Watt. 2007. Assessing corewood acoustic velocity and modulus of elasticity with two impact based instruments in 11-year-old trees from a clonal-spacing experiment of Pinus radiata D. Don. For. Ecol. Manage. 239(1-3): 217221. DOI 10.1016/j.foreco.2006.12.009.

Legg, M. and S. Bradley. 2016. Measurement of stiffness of standing trees and felled logs using acoustics: A review. Acoust. Soc. Am. 139(2): 588-604. DOI 10.1121/1.4940210.

Lotan, J.E. and W.B. Critchfield. 1990. Pinus contorta (Dougl. Ex. Loud.) Lodgepole pine. In: Silvics of North America. Vol. 1. Conifers, agric. Handb. 654, R. M. Burns and B. H. Honkala, (Eds.). USDA For. Serv., Washington, DC: pp: 648-668.

Mallows, C. L. 1973. "Some Comments on CP". Technometrics 15 (4): 661-675. doi:10.2307/1267380

Merlo, E., J.G. Alvarez-Gonzalez, O. Santaclara and G. Riesco. 2014. Modelling modulus of elasticity of Pinus pinaster Ait. in northwestern Spain with standing tree acoustic measurements, tree, stand and site variables. For. Syst. 23(1): 153-166. DOI 10.5424/fs/ 2014231-04706.

Middleton, G.R. and B.D. Munro. 2013. Characterizing the wood attributes and product potential of 60-year-old hem-fir in coastal British Columbia. In: Information Report. FPInnovations, Vancouver, B.C.

Miles, P.D. and W.B. Smith. 2009. Specific gravity and other properties of wood and bark for 156 tree species found in North America. Res. Note NRS-38. Newtown Square, PA. U.S. Department of Agriculture, Forest Service, Northern Research Station. 35 p.

Moore, J.R., A.J. Lyon, G.J. Searles, S.A. Lehneke and D.J. RidleyEllis. 2013. Within- and between-stand variation in selected properties of Sitka spruce sawn timber in the UK: Implications for segregation and grade recovery. Ann. Forest Sci. 70(4): 403-415. DOI 10.1007/s13595-013-0275-y.

Mora, C.R., L.R. Schimleck, J.M. Mahon, F. Isik, A. Clark and R.F. Daniels. 2009. Relationships between acoustic variables and different measures of stiffness in standing Pinus taeda trees. Can. J. For. Res. 39(8): 1421-1429. DOI 10.1139/x09-062.

Mortyn, J., I. Duchesne and N. Shabani. 2015. Effect of late-age commercial thinning in lodgepole pine on the volume and value of lumber. In: FPInnovations Research Report. Point Claire, Quebec.
Murphy, G.E. and D. Amishev. 2008. Effects of bark removal on acoustic velocity of Douglas-fir logs. New Zeal. J. For. Sci. 38(2/3): 247-252.

Murphy, G.E. and D. Cown. 2015. Stand, stem and log segregation based on wood properties: A review. Scand. J. For. Res. 30(8): 757770. DOI 10.1080/02827581.2015.1055791.

Paradis, N., D. Auty, P. Carter and A. Achim. 2013. Using a standing-tree acoustic tool to identify forest stands for the production of mechanically-graded lumber. Sensors (Basel) 13(3): 3394-3408. DOI 10.3390/s130303394.

Pinheiro, J., D. Bates, S. DebRoy, D. Sarkar and R.C. Team. 2020. Nlme: Linear and nonlinear mixed effects models. R package version 3.1-145.

Raymond, C.A., B. Joe, R. Evans and R.L. Dickson. 2007. Relationship between timber grade, static and dynamic modulus of elasticity, and Silviscan properties for Pinus radiata in New South Wales. New Zeal. J. For. Sci. 37(2): 186-196.

Raymond, C.A., B. Joe, D.W. Anderson and D.J. Watt. 2008. Effect of thinning on relationships between three measures of wood stiffness in Pinus radiata: Standing trees vs. logs vs. short clear specimens. Can. J. For. Res. 38(11): 2870-2879. DOI 10.1139/x08-124.

R Core Team (2013). R: A language and environment for statistical computing. R Foundation for Statistical Computing, Vienna, Austria. URL http://www.R-project.org/.

Reineke, L.H. 1933. Perfecting a stand-density index for even-aged forests. J. Agric. Res. 46: 627-638.

Schwarz, G.E. 1978. Estimating the dimension of a model. Ann. Stat. 6 (2): 461-464, doi:10.1214/aos/1176344136.

Stewart, J.D., T.N. Jones and R.C. Noble. 2006. Long-term Lodgepole Pine Silviculture Trials in Alberta: History and Current Results. Edmonton, AB: NRCan, Can. For. Serv. and Foothills Model Forest. Todoroki, C.L. and E.C. Lowell. 2016. Validation of models predicting modulus of elasticity in Douglas-fir trees, boles, and logs. New Zeal. J. For. Sci. 46(1): 11. DOI 10.1186/s40490-016-0067-x.

Wagner, F.G., T.M. Gorman and S.Y. Wu. 2003. Assessment of intensive stress-wave scanning of Douglas-fir trees for predicting lumber MOE. Forest Prod. J. 53(3): 89-92.

Wang, X. 2013. Acoustic measurements on trees and logs: A review and analysis. Wood Sci. Technol. 47(5): 965-975. DOI 10.1007/ s00226-013-0552-9.

Wang, X. and R.J. Ross. 2008. Acoustic evaluation of Alaskan young-growth wood. In: 15th International Symposium on Nondestructive Testing of Wood, September 10-12, 2007. Duluth, Minnesota.

Wang, X., P. Carter, R.J. Ross and B.K. Brashaw. 2007. Acoustic assessment of wood quality of raw forest materials - a path to increased profitability. Forest Prod. J. 57(5): 6-14.

Watt, M.S. and G. Trincado. 2014. Modelling between tree and longitudinal variation in green density within Pinus radiata: Implications for estimation of MOE by acoustic methods. New Zeal. J. For. Sci. 44(16): 1-10. DOI 10.1186/s40490-014-0016-5.

Whitehead, R.J. and G.L. Russo. 2005. Beetle-proofed lodgepole pine stands in interior British Columbia have less damage from mountain pine beetle. Information Report Natural Resources Canada, Canadian Forest Service, Pacific Forestry Centre Victoria, British Columbia.

Wielinga, B., C.A. Raymond, R. James and A.C. Matheson. 2009. Effect of green density values on Pinus radiata stiffness estimation using a stress-wave technique. New Zeal. J. For. Sci. 39(2-3): 71-83. DOI 10.1080/03014220909510565. 